\title{
Epidemiology of chronic Pseudomonas aeruginosa infections in the airways of lung transplant recipients with cystic fibrosis
}

Siegbert Walter, Peter Gudowius, Jutta Boßhammer, Ute Römling, Hartmut Weißbrodt, Wolfgang Schürmann, Horst von der Hardt, Burkhard Tümmler

\section{Kinderklinik der Universität Leipzig, D-04317 Leipzig, Germany \\ $S$ Walter \\ Klinische \\ Forschergruppe, \\ Zentrum Biochemie \\ and Zentrum \\ Kinderheilkunde, \\ OE 6710 \\ $S$ Walter \\ P Gudowius \\ J Boßhammer \\ U Römling \\ $H$ von der Hardt \\ B Tümmler}

Zentrum

Laboratoriumsmedizin

Abteilung

Medizinische

Mikrobiologie,

OE 5210

$\mathrm{H}$ Weißbrodt

Zentrum Innere

Medizin and

Dermatologie,

Abteilung

Pneumologie, OE 6870

W H T Schürmann

Zentrum

Kinderheilkunde and

Pädiatrische

Pneumologie, OE 6710

$\mathrm{H}$ von der Hardt

Medizinische

Hochschule Hannover,

D-30623 Hannover,

Germany

Microbiology and

Tumor Biology Center,

Karolinska Institutet,

S-17177 Stockholm,

Sweden

U Römling

Correspondence to: Dr S Walter, Zentrum Biochemie and Zentrum

Kinderheilkunde, OE 6710

Medizinische Hochschule

Hannover, Konstanty

Gutschow Str. 8, D-30623

Hannover, Germany.

Received 11 June 1996

Returned to authors

23 September 1996

Revised version received

14 November 1996

Accepted for publication

19 November 1996

\begin{abstract}
Background - The source of airway colonisation with Pseudomonas aeruginosa is not well defined in patients with cystic fibrosis after lung transplantation. Using a DNA-based typing system a study was undertaken to investigate whether lung transplant recipients acquired new strains of $P$ aeruginosa or retained those they had before transplantation.
\end{abstract}

Methods - Seventy four $P$ aeruginosa isolates taken before and after transplantation were analysed from 11 patients with cystic fibrosis who had undergone lung transplantation in the Medical School of Hannover between 1988 and 1994 . The genetic relatedness of the $74 P$ aeruginosa strains was evaluated from macrorestriction fragment pattern similarity.

Results - Each of the 11 lung transplant recipients harboured one identical $P$ aeruginosa clone before and after transplantation. The airways of four of the 11 patients were preoperatively colonised by two or three different clones, but six months after transplantation only one clone was detectable.

Conclusions - These results show that there is no change in the $P$ aeruginosa population in the airways of lung transplant recipients before and after transplantation and it is assumed that the chronic drainage of $P$ aeruginosa into the lung allografts is caused by the bacterial reservoir in the paranasal sinuses and the trachea.

(Thorax 1997;52:318-321)

Keywords: lung transplantation, cystic fibrosis, Pseudomonas aeruginosa.

Double lung transplantation has become a recognised and established treatment for adults and children in terminal respiratory failure resulting from cystic fibrosis. One of the major problems in the early postoperative period is infectious bronchopulmonary complications caused by viruses, bacteria, and fungi. ${ }^{1} \mathrm{Al}-$ though the cystic fibrosis specific epithelial membrane defect does not recur in lung transplants, ${ }^{2}$ it seems that the upper airways, particularly the sinuses and the trachea, remain a bacterial reservoir after surgery. ${ }^{34}$ Using macrorestriction fragment pattern analysis as a DNAbased typing system we investigated whether lung transplant recipients in our clinic infected with Pseudomonas aeruginosa acquired new strains or retained their strains which they harboured before lung transplantation. The results might have direct implications for the clinical and perioperative management.

A previous study by Tsang et $a \bar{P}$ showed that three of the four lung transplant recipients with cystic fibrosis who harboured $P$ aeruginos $a$ were colonised postoperatively by genotypes which were different from those carried before the transplantation. Only in one transplant recipient with cystic fibrosis were the preoperative and postoperative isolates identical. Analysis of the origin of Burkholderia cepacia infection after lung transplantation in patients with cystic fibrosis indicated that the upper airways could be a source of bacterial colonisation or reinfection of the lung allografts. ${ }^{6}$

\section{Methods}

PATIENT POPULATION, BRONCHOALVEOLAR

LAVAGE, AND BACTERIAL STRAINS

$P$ aeruginosa strains were isolated from 11 lung transplant recipients with cystic fibrosis (five men) of mean age 28.8 years (range 23.5-32.1) who had undergone lung transplantation in the Medical School of Hannover between 1988 and 1994 (table 1). With the exception of patient 2 who had a heart-lung transplant, all other patients received bilateral lung transplantation with bronchial anastomosis. All patients were colonised before and after lung transplantation with $P$ aeruginosa.

Preoperative isolates were retrieved from sputum samples and postoperative isolates from bronchoalveolar lavage (BAL) fluid. Sputum samples were homogenised by vortexing with sterile glass beads for one minute. An aliquot was diluted 1:1000 in phosphate buffer saline (PBS). Undiluted and diluted specimens (50 $\mu$ l each) were plated onto Columbia blood agar (Unipath, Wesel, Germany), MacConkey agar (Unipath), and chocolate agar (Unipath). BAL fluid samples were taken by fibreoptic bronchoscopy from the middle lobe. After placing the bronchoscope in a wedge position, six aliquots of $0.9 \%(\mathrm{w} / \mathrm{v})$ sodium chloride solution $(20 \mathrm{ml}$ each) were instilled into segment 4 or 5. The recovery of the first aliquot was discarded to make sure that the lavage was taken from the alveolar compartment rather than the small airways. The mean recovery rate was $55 \%$. Seventy four isolates of $P$ aeruginos $a$ with different phenotypes one week before, one week 
Table 1 Clinical characteristics of lung transplant recipients with cystic fibrosis (CF)

\begin{tabular}{|c|c|c|c|c|c|c|c|c|c|}
\hline $\begin{array}{l}\text { Patient } \\
\text { no. }\end{array}$ & Sex & $\begin{array}{l}\text { Age at } \\
\text { diagnosis of } \\
C F\end{array}$ & CFTR genotype & $\begin{array}{l}\text { Age at onset } \\
\text { of chronic } \\
P \text { aeruginosa } \\
\text { infection (years) }\end{array}$ & $\begin{array}{l}\text { Age at } \\
\text { transplantation } \\
\text { (years) }\end{array}$ & $\begin{array}{l}\text { First } P \text { aeruginosa } \\
\text { infection after } \\
\text { transplantation } \\
\text { (days) }\end{array}$ & $\begin{array}{l}\text { No. of } P \text { aeruginosa } \\
\text { infections after } \\
\text { transplantation }\end{array}$ & $\begin{array}{l}\text { Cooper } \\
\text { index }^{1}\end{array}$ & 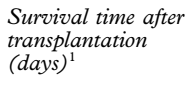 \\
\hline 1 & $M$ & 5 years & Rare unknown & 21 & 21 & 30 & 1 & BOS 0a & 438 \\
\hline 2 & $M$ & 2 years & dF508/dF508 & 9 & 22 & 1431 & 2 & BOS 0a & 2643 \\
\hline 3 & $M$ & 12 years & dF508/dF508 & 17 & 21 & - & 0 & BOS 0a & 462 \\
\hline 4 & $M$ & 10 months & dF508/R553X & 12 & 30 & 136 & 4 & BOS $2 a$ & 746 \\
\hline 5 & $\mathrm{~F}$ & 12 years & dF508/2789+5G-A & 18 & 25 & - & 0 & BOS 0a & 1319 \\
\hline 6 & $\mathrm{~F}$ & 12 years & $\mathrm{dF} 508 / \mathrm{dF} 508$ & 13 & 21 & 145 & 3 & BOS $2 a$ & 1604 \\
\hline 7 & $\mathrm{~F}$ & 18 years & dF508/dF508 & 18 & 28 & 687 & 2 & BOS $2 b$ & 1312 \\
\hline 8 & $M$ & 9 months & dF508/unknown & 17 & 21 & - & 0 & BOS 0a & 1512 \\
\hline 9 & $\mathrm{~F}$ & 12 years & dF508/dF508 & 15 & 23 & 317 & 4 & BOS 0a & 1359 \\
\hline 10 & $\mathrm{~F}$ & 19 years & dF508/dF508 & 19 & 27 & & 0 & BOS 0a & 1321 \\
\hline 11 & $\mathrm{~F}$ & 10 months & dF508/2184insA & 14 & 19 & 795 & 3 & BOS $3 b$ & $1452^{2}$ \\
\hline
\end{tabular}

Cooper index: $\mathrm{BOS}=$ bronchiolitis obliterans syndrome; stages $0=$ no abnormality, $1=$ mild, $2=$ moderate, $3=$ severe; subcategory a $=$ absence of pathological evidence of bronchiolitis obliterans; $\mathrm{b}=$ presence of bronchiolitis obliterans pathologically. ${ }^{12}$

${ }^{1}$ Referring to 28 February 1996.

${ }^{2}$ Deceased.

after, and six months after transplantation were characterised by macrorestriction analysis. Based on the results in previous studies, the BAL fluid was considered to be not contaminated, or only marginally so, if the specimen contained $<10^{2}$ colony forming units $(\mathrm{CFU}) / \mathrm{ml}$ of oropharyngeal flora, no ciliated epithelial cells, and $<1 \%$ squamous epithelial cells. $^{7-9}$

\section{MACRORESTRICTION ANALYSIS}

The genotyping of the $P$ aeruginosa strains was carried out as described previously. ${ }^{10}$ Briefly, the agarose-embedded $P$ aeruginosa DNA was digested by $S p e$ I and the resulting fragments were separated using a CHEF DRII or CHEF DRIII apparatus (BioRad, Richmond, California, USA). Running conditions in $1 \%$ agarose gels were electric field strength $6 \mathrm{~V} / \mathrm{cm}$, linear ramping 5-25 seconds for 20 hours and 5-60 seconds for 17 hours in $0.5 \times$ Tris-borateEDTA (TBE) buffer. $\lambda$ Bst EII digest, $\lambda$ phage DNA oligomers, Spe I digested $P$ aeruginosa $\mathrm{C},{ }^{11}$ and PAO (DSM 1707) were used as size markers and restriction digestion fingerprints of reference strains. Fragment patterns on the same gel were compared visually side by side. The relatedness of patterns of the strains was then evaluated by computerised cluster analysis. ${ }^{10}$ Two $P$ aeruginosa isolates are members of a clonal lineage if they share $>75 \%$ of Spe I bands. ${ }^{10}$ Of the isolates from a specimen of sputum or BAL fluid with identical Spe I fragment patterns, one representative strain was selected for a second macrorestriction analysis. In total, 33 isolates were rerun to ascertain the pairwise fragment pattern similarity in quantitative terms. Clones and clonal variants that were identical were indicated with the same letters.

\section{Results}

MICROBIOLOGICAL RESULTS

The genotyping indicated that each of the 11 lung transplant recipients harboured at least one identical clone or a clonal variant of a $P$ aeruginosa strain preoperatively and postoperatively but each patient harboured a different clone (table 2). Two of the 11 patients were preoperatively colonised with three different genotypes. One week after transplantation one of these was colonised with two different and the other with only one genotype. Six months after transplantation only one clone persisted in each of these patients. Of the two patients who were carrying two different genotypes before transplantation, one harboured two different clones one week after transplantation and the other retained only a single strain. Six months after transplantation only one genotype was isolated in the airways of both patients (fig 1 ). The isolates of $P$ aeruginosa of the lung transplant recipients after lung transplantation were mostly mucoid LPSrough strains specific for chronic respiratory infections of patients with cystic fibrosis. ${ }^{10}$ They did not change their cystic fibrosis specific morphology in the lung allografts.

\section{CLINICAL RESULTS}

Clinical characteristics of the studied patients are summarised in table 1. Cystic fibrosis was diagnosed at a mean age of 8.6 years (range 9 months to 19 years). The mean age at onset of the chronic $P$ aeruginosa infection was 15.7 years (range 9-21) and at lung transplantation it was 23.5 years (range 19-30).

The Cooper index ${ }^{1213}$ was used as a standardised method for assessing functional results after lung transplantation. In this staging system four grades of bronchiolitis obliterans syndrome (BOS), with (a) or without (b) histo-

Table 2 Molecular epidemiology of Pseudomonas aeruginosa in lung allografts of lung transplant recipients with cystic fibrosis

\begin{tabular}{llll}
\hline & \multicolumn{2}{l}{ Paeruginosa genotypes* } \\
\cline { 2 - 4 } $\begin{array}{l}\text { Patient } \\
\text { no. }\end{array}$ & $\begin{array}{l}\text { Before } \\
\text { transplantation }^{1}\end{array}$ & $\begin{array}{l}\text { After } \\
\text { transplantation }^{2}\end{array}$ & $\begin{array}{l}\text { Six months after } \\
\text { transplantation }^{2}\end{array}$ \\
\hline 1 & ab, ac, ad & ab, ac & ab \\
2 & C, af, ag & C & C \\
3 & ah & ah & ah \\
4 & ai & ai & ai \\
5 & aj & aj & aj \\
6 & ak & ak & ak \\
7 & al, am & al, am & al \\
8 & an & an & an \\
9 & ao, ap & ao & ao \\
10 & aq & aq & aq \\
11 & ar & ar & ar \\
\hline
\end{tabular}

${ }^{1}$ Sputum or throat swab; ${ }^{2}$ Bronchoalveolar lavage fluid. * Clones and clonal variants already identified in recent studies ${ }^{10}$ are indicated with the same capital letter. Novel genotypes were given two small letters. 


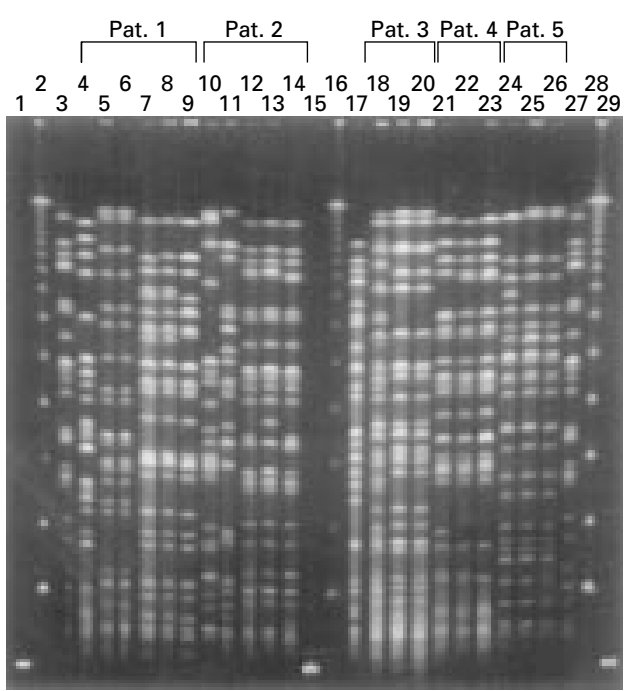

Figure 1 Genotyping of Pseudomonas aeruginosa isolates of five of the 11 lung transplant recipients with cystic fibrosis. Spe I fragment patterns of patient strains one week before $(p)$, one week after ( $p o)$, and six months after transplantation (sma) (lanes 4-14, 18-26). Lanes 1, 15, 29: $\lambda$ Bst EII digests; lanes 2, 16, 28: $\lambda$ oligomers; lanes 3, 27: Spe I digests of $P$ aeruginosa $C$ (11) chromosome; lane 17: Spe I digest of P aeruginosa PAO (DSM 1707) chromosome. Genotypes of patient strains: lanes 4-9: patient 1 , lane 4 ad $(p)$, lanes 5-6 ac ( $p, p o)$, lanes 7-9 $a b$ ( $p, p o, s m a)$, lane 9 clonal variant of strain $a b$; lanes 10-14: patient 2, lane 10 af $(p)$, lane 11 ag ( $p)$, lanes $12-14 C(p, p o$, sma), lane 13 clonal variant of strain $C$; lanes 18-20: patient 3, ah ( $p$, po, sma), lane 18 clonal variant of strain ah; lanes 21-23: patient 4, ai ( $p, p o$, sma); lanes 24-26: patient 5: aj (p, po, sma), lane 24 clonal variant of strain aj.

pathological evidence of obliterative bronchiolitis (BOS grades $0-3$, subcategories a and b), are defined using the forced expiratory volume in one second $\left(\mathrm{FEV}_{1}\right)$ as an indicator of graft dysfunction. In our population of patients with cystic fibrosis who had undergone lung transplantation seven of the 11 lung recipients (64\%) had a Cooper index of BOS 0a (no significant abnormality), correlating to the results of the Washington University Lung Transplant Group, ${ }^{12}$ and a mean present survival time of 1293 days (range 438-2643). Three patients were graded as BOS 2 (moderate obliterative bronchiolitis syndrome) with a mean survival time of 1220 days (range 746-1604). Seven of the 11 patients experienced acute episodes of infections with $P$ aeruginosa defined by expectoration of mucopurulent secretions, with or without decline in $\mathrm{FEV}_{1}$, and $P$ aeruginosa colony forming units (CFU) of $>10^{4}$ / $\mathrm{ml}$ in the BAL fluid and were treated with antipseudomonal chemotherapy. One patient (no. 11) died 1452 days after the lung transplantation due to a chronic progressive $P$ aeruginosa infection; a second patient (no. 4) who has survived for 746 days since lung transplantation has recurrent mucopurulent bronchitic $P$ aeruginosa infections requiring intravenous antibiotic treatment every three months; and a third patient (no. 9) who has survived for 1359 days since lung transplantation has frequent infections but has not needed regular antibiotic treatment so far.

\section{Discussion}

Lung transplantation or combined heart-lung transplantation has emerged as a therapeutic intervention for cystic fibrosis patients with end stage respiratory failure. ${ }^{14}$ Undoubtedly, lung transplantation improves the quality of life of most of the patients and all efforts should be made to optimise this treatment.

Our genotype analysis shows that all 11 lung transplant recipients harboured different $P$ aeruginosa strains, but each of the patients remained colonised with the same strain as was cultured before lung transplantation. These results are in conflict with those of Tsang $e t a \bar{l}^{\bar{T}}$ who used the pCMTox probe for strain typing. ${ }^{15}$ This probe recognises restriction fragment length polymorphisms in a region of high genomic variability ${ }^{111617}$ ( $\mathrm{T}$ Heuer, personal communication) and it is tempting to assume that the shift of the habitat by transplantation is associated with genome rearrangements in the $P$ aeruginosa clone. Hence, a probe such as pCMTox which scans a single hypervariable locus may indicate a change, whereas the global genome-wide fragment pattern may undergo no or minor shifts.

Our genotype data support the hypothesis that a reservoir of $P$ aeruginosa remains in patients with cystic fibrosis who undergo lung transplantation, presumably in the upper respiratory tract or trachea. Recolonisation by these potentially multiresistant pathogens may cause infectious complications of the lung allografts and, combined with the impaired mucociliary clearance after lung transplantation and the immunosuppression, this creates a high risk of graft infection following lung transplantation. ${ }^{18}$ Some transplantation groups therefore recommend surgical drainage of the sinuses before transplantation, ${ }^{19-22}$ while other centres prescribe lifelong inhalation of antimicrobial agents to reduce the risk of reinfection or colonisation with $P$ aeruginos a from the upper airways. ${ }^{1423}$

The Stanford group developed a management strategy which combined endoscopic surgery with an initial topical antimicrobial treatment course and serial long term monthly sinus antimicrobial lavage. ${ }^{19-21}$ They reduced the need for reoperation for chronic sinusitis and reported that eight long term survivors required only one seven-day admission to hospital and parenteral antimicrobial agents against $P$ aeruginosa infections during a follow up period of 3200 days after lung transplantation. Davidson et al introduced a similar protocol ${ }^{22}$ in which sinus surgery was followed by daily saline nasal irrigation with fluid containing tobramycin. With this regimen the sputum of all patients with cystic fibrosis who had undergone lung transplantation was free of $P$ aeruginosa and bacterial pneumonia was not reported. The Harefield group prescribed lung transplant recipients with a lifelong inhalation containing colistin sulphate via a face mask at a dose of 1 mega unit twice a day in the first three postoperative months reduced thereafter to 1 mega unit daily. ${ }^{1423}$ In spite of these measures, and an additional course with antipseudomonal antibiotics for the first 10 
postoperative days, the 79 lung transplant recipients studied had $43 P$ aeruginosa respiratory infections during the first three months after transplantation and 11 infections during each of months 4-6 and 7-12.

However, most lung transplantation groups do not carry out preoperative sinus surgery, either because they do not feel that sinus disease adversely affects the long term outcome of their patients ${ }^{24}$ or because of the complications involved in sinus surgery. Stammberger and Wolf, ${ }^{25}$ however, reported only two cases of cerebrospinal fluid rhinorrhoea and no intracranial or ophthalmic complications in a series of over 4000 cases of functional sinus surgery.

As it is important to protect lung allografts from acquiring $P$ aeruginosa from the upper airways, we plan to modify our perioperative management of lung transplant recipients. A prospective study is planned in which we will investigate whether sinus surgery combined with antimicrobial lavage or long term inhalation of nebulised antimicrobial agents via a face mask reduces the risk of postoperative infection in lung transplant recipients with cystic fibrosis.

We thank J Greipel for his help in the computerised cluster analysis and $\mathrm{T}$ Heuer for communication of unpublished analyses of genome plasticity of $P$ aeruginosa. This work was supported by the Deutsche Forschungsgemeinschaft. SW is a fellow of the Walter-Marget-Vereinigung e.V.

1 Tsang V, Hodson ME, Yacoub MH. Lung transplantation for cystic fibrosis. Br Med Bull 1992;48:949-71.

2 Wood A, Higenbottam T, Jackson M, Scott J, Stewart S, Wallwork J. Airway mucosal bioelectric potential difference in cystic fibrosis after lung transplantation. Am Rev Respir Dis 1989;140:1645-9.

3 Knowles MR, Stutts MJ, Spock A, Fisher N, Gatzy JT, Boucher RC. Abnormal permeation through cystic fibrosis respiratory epithelium. Science 1983;221:1067-70.

4 Taylor CJ, McGaw J, Howden R, Duerden BI, Baxter PS. Bacterial reservoirs in cystic fibrosis. Arch Dis Child 1990; 65:175-7.

5 Tsang V, Pitt TL, Kaufmann ME, Gaya H, Hodson ME, Yacoub M. Colonisation of lung allografts with Pseudomonas aeruginosa in heart-lung transplant recipients with cystic fibrosis. Thorax 1994;49:721-2.

6 Steinbach S, Sun L, Jiang RZ, Flume P, Gilligan P, Egan TM, et al. Transmissibility of Pseudomonas cepacia infection in clinic patients and lung transplant recipients with cystic fibrosis. N Engl f Med 1994;331:981-7.
7 Thorpe JE, Baugham RP, Frame PT, Wesseler TA, Staneck $\mathrm{JL}$. Bronchoalveolar lavage for diagnosing acute bacteria pneumonia. F Infect Dis 1987;155:855-61.

$8 \mathrm{Kahn}$ FW, Jones JM. Diagnosing bacterial respiratory infection by bronchoalveolar lavage. F Infect Dis $1987 ; 155$ $862-9$.

9 Lode H, Schaberg T, Raffenberg M, Mauch H. Diagnostic problems in lower respiratory tract infections. $\mathcal{F}$ Antimicrob Chemother 1993;32:29-37.

10 Römling U, Fiedler B, Bosshammer J, Grothues D, Greipel J, von der Hardt H, et al. Epidemiology of chronic Pseudomonas aeruginosa infections in cystic fibrosis. F Infect Dis 1994;170:1616-21.

11 Schmidt KD, Tümmler B, Römling U. Comparative genome mapping of Pseudomonas aeruginosa $\mathrm{PAO}$ with $P$ aeruginos $\mathrm{C}$, which belongs to a major clone in cystic fibrosis patients

12 Sundaresan S, Trulock EP, Mohanakumar T, Cooper JD, Patterson GA, and the Washington Lung Transplant Group. Prevalence and outcome of bronchiolitis obliterans syndrome after lung transplantation. Ann Thorac Surg 1995;60:1341-7.

13 Cooper JD, Billingham M, Egan T, et al. A working formulation for the standardization of nomenclature and clinical staging of chronic dysfunction in lung allografts. f Heart Lung Transplant 1993;12:713-6.

14 Madden BP, Hodson ME, Tsang V, Radley-Smith R Khaghani A, Yacoub MY. Intermediate-term results of heart-lung transplantation for cystic fibrosis. Lancet 1992; 339:1583-7.

15 Ogle JW, Janda JM, Woods DE, Vasil ML. Characterization and use of a DNA probe as an epidemiological marker for Pseudomonas aeruginosa. F Infect Dis 1987;155:119-26.

16 Pritchard AE, Vasil ML. Possible insertion sequences in mosaic genome organization upstream of the exotoxin A gene in Pseudomonas aeruginosa. F Bacteriol 1990;172

17 Sokol PA, Luan MZ, Storey DG, Thirukkumaran P. Genetic rearrangement associated with in vivo mucoid conversion of Pseudomonas aeruginosa PAO is due to insertion elements. F Bacteriol 1994;176:553-62.

18 Shankar S, Fulsham L, Read R, Theodoroupoulos S, Cole $\mathrm{P}$, Madden $\mathrm{B}$, et al. Mucociliary function after lung transplantation. Transplant Proc 1991;23:1222-3.

19 Umetsu DT, Moss RB, King VV, Lewiston NJ. Sinus disease in patients with severe cystic fibrosis: relation to pulmonary exacerbation. Lancet 1990;335:1077-8.

20 Lewiston N, King V, Umetsu D, Starnes V, Marshall S Kramer M, et al. Cystic fibrosis patients who have undergone heart-lung transplantation benefit from maxillary sinus antrostomy and repeated sinus lavage. Transplant Proc 1991;23:1207-8.

21 Moss RB, King VV. Management of sinusitis in cystic fibrosis by endoscopic surgery and serial antimicrobial lavage. Arch Otolaryngol Head Neck Surg 1995;121:566-72.

22 Davidson TM, Murphy C, Mitchell M, Smith C, Light M. Management of chronic sinusitis in cystic fibrosis. Laryngoscope 1995;105:354-8.

23 Madden BP, Kamalvand K, Chan CM, Khaghani A, Hodson $M E$, Yacoub $M$. The medical management of patients with cystic fibrosis following heart-lung transplantation. Eur Respir 7 1993;6:965-70.

24 Flume PA, Egan TM, Paradowski LJ, Detterbeck FC, Thompson JT, Yankaskas JR. Infectious complications of lung transplantation: impact of cystic fibrosis. Am $\mathcal{F}$ Respir Crit Care Med 1994;149:1601-7.

25 Stammberger $\mathrm{H}$, Wolf $\mathrm{G}$. Headaches and sinus disease: the endoscopic approach. Ann Otol Rhinol Laryngol 1988;97: 3-23. 